Aksaray University
Journal of Science and Engineering
e-ISSN: 2587-1277
http://dergipark.gov.tr/asujse
http://asujse.aksaray.edu.tr

Research Article

\title{
Proportional Counter in X-Ray Fluorescence
}

\author{
Hiwa Mohammad Qadr ${ }^{*}$ \\ Department of Physics, College of Science, University of Raparin, Sulaimanyah, Iraqi Kurdistan, Iraq
}

-Received Date: May 15, 2020

-Revised Date: Jan 28, 2021

-Accepted Date: Feb 02, 2021

-Published Online: Feb 03, 2021

\begin{abstract}
The purpose of this work is to investigate and quantify $\mathrm{x}$-ray fluorescence, its production and its spectroscopy. Characteristic x-ray with different energies was obtained from six various elements using Am-241 source with $59.5 \mathrm{keV}$. It was found that x-ray energy and intensity increase with increasing atomic number of material. X-ray spectroscopy was studied for such elements in respect to their atomic number and intensity of $\mathrm{K}_{\alpha}$ using proportional counter. Furthermore, $\mathrm{x}$-ray fluorescence was produced from different thicknesses of copper foil using different energies. It was found that there is no substantial difference in x-ray fluorescence yield with higher thickness of the target.
\end{abstract}

\section{Keywords}

Characteristic X-ray, X-ray fluorescence, Various element, Radioactive sources

\section{INTRODUCTION}

Nowadays, X-ray is important in many section of life. It is invaluable in many applied fields of science such as radiology, nuclear energy and radiation damage [1-6]. In 1895, W. Röntgen discovered X-rays which are produced when a beam of electrons interacts a target [7]. X-ray can also be produced by the interaction of energetic photons incident on a metallic target via the photoelectric absorption. The subsequent de-excitation of the ions in the material creates a characteristic $\mathrm{x}$-ray spectrum of the material $[8,9]$. This type of radiation has wave-particle duality [10]. X-ray photons are less penetrating than gamma-ray photons, depending on the

*Corresponding Author: hiwa.physics@uor.edu.krd, @0000-0001-5585-3260 
energy $[11,12]$. However, lead is still of choice for shielding of x-ray due to its high density and atomic number.

Proportional counter is widely used in doing x-ray work as being a sensitive detector of moderate energy resolution [13]. This detector consists of a cylinder and a thin wire containing a gas at a given pressure. X-rays enter through a thin window and create ion-electron pair which are separated by an applied bias. A proportional counter can be used for spectroscopy of a wide range of radiation. Energy resolution of this type is typically a few percent, in a range of about $5 \mathrm{keV}$ to $25 \mathrm{keV}$, peak energies can be determined to within $1 \mathrm{keV}[14,15]$. However, it has a lower detection efficiency and poorer energy resolution than other detectors [16]. In this work, $\mathrm{x}$-ray was used to excite atoms of different elements of low, medium and high atomic number.

\section{EXPERIMENTAL METHODS}

Fig. 1 shows the block diagram for the experimental system. In this paper, the characteristic xrays produced for six different target elements as shown in Table 1. A proportional counter filled with xenon gas to detect x-rays from a number of different sources. The detector window is made of very low atomic number material of $\mathrm{Be}(\mathrm{Z}=4)$ which allows for low energy to penetrate. The system was calibrated using two radioactive sources. Am-241 was used for its gamma energy photon at $59.5 \mathrm{keV}$ and characteristic x-ray at $17.75 \mathrm{keV}$. Also, Fe-55 was used for characteristic $\mathrm{x}$-ray at $5.89 \mathrm{keV}$. The calibrated was done to ensure a range of energy (5- 60 $\mathrm{keV}$ ) which is covered. Thus, a characteristic x-ray of interest is identified. X-ray source was placed close to the proportional counter and target elements which were rotated to obtain the spectrum. These targets have different atomic numbers and variable energy. When the gamma rays interact with electrons of the targets via the photoelectric effect, the rearrangement of the electrons in the ionized atoms produce characteristic x-rays with energy that equal to the difference in the electronic energy levels.

Table 1. Target elements used in obtaining characteristic X-ray.

\begin{tabular}{cccc}
\hline Targets & Atomic number & Energy of $\mathbf{K}_{\boldsymbol{\alpha}}(\mathbf{k e V})$ & Energy of $\mathbf{K}_{\boldsymbol{\beta}}(\mathbf{k e V})$ \\
\hline $\mathrm{Cu}$ & 29 & 8.038 & 8.91 \\
$\mathrm{Rb}$ & 37 & 13.37 & 14.97 \\
$\mathrm{Mo}$ & 42 & 17.44 & 19.63 \\
$\mathrm{Ag}$ & 47 & 22.10 & 24.99 \\
$\mathrm{Ba}$ & 56 & 32.06 & 36.55 \\
$\mathrm{~Tb}$ & 65 & 44.23 & 50.65 \\
\hline
\end{tabular}


X-ray fluorescence (XRF) was produced using copper foil. Different thicknesses were applied with different energies to study any variation in intensity of x-ray produced. The direct beam coming from the $\mathrm{x}$-ray source was directed to hit the target $\mathrm{Cu}$.

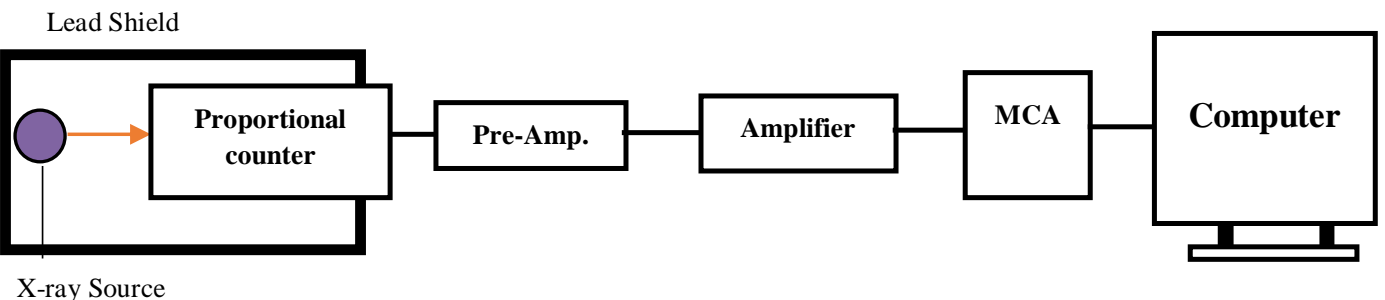

Figure 1. A block diagram of the experimental setup.

\section{RESULT AND DISCUSSION}

The proportional counter should be calibrated before using in radiation detection to covert channel number to energy scale. The calibration of the spectrum was carried out using three energies, $17.75 \mathrm{keV}$ and $59.5 \mathrm{keV}$ from Am-241 and $5.89 \mathrm{keV}$ from Fe-55 radioactive source. These energies have different atomic numbers. The reason these two particular sources were chosen simply because of the low energies. Fig. 2 shows the energy peaks used for calibration of the spectrum. This spectrum was calibrated between 5.89 to $59.5 \mathrm{keV}$. So that, energies of $\mathrm{X}$-ray in this range can be identified.

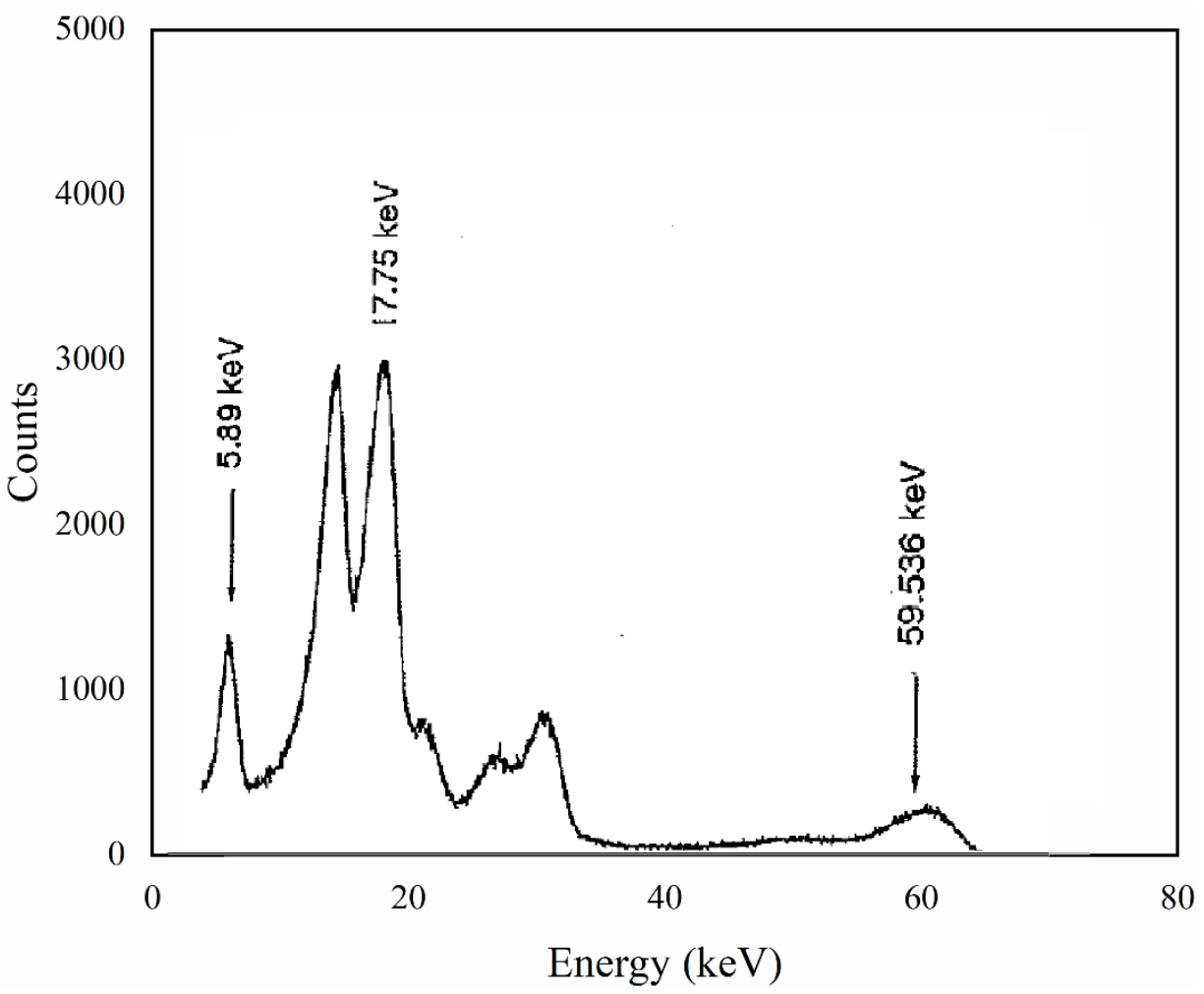

Figure 2. Energy spectrum and calibrated for Fe-55 and Am-241 radioactive sources. 
The energy resolution is obtained from Full Width at Half Maximum (FWHM) of a single peak using the following equation [17-19]:

$$
R \%=\frac{F W H M}{E_{0}} \times 100
$$

Where $\mathrm{R}$ is energy resolution and $\mathrm{E}_{0}$ is the related energy. It can be seen from Fig. 3 that the FWHM value increase with increasing the energy value. Thus, the poor resolution obtained as the energy of the photon increased.

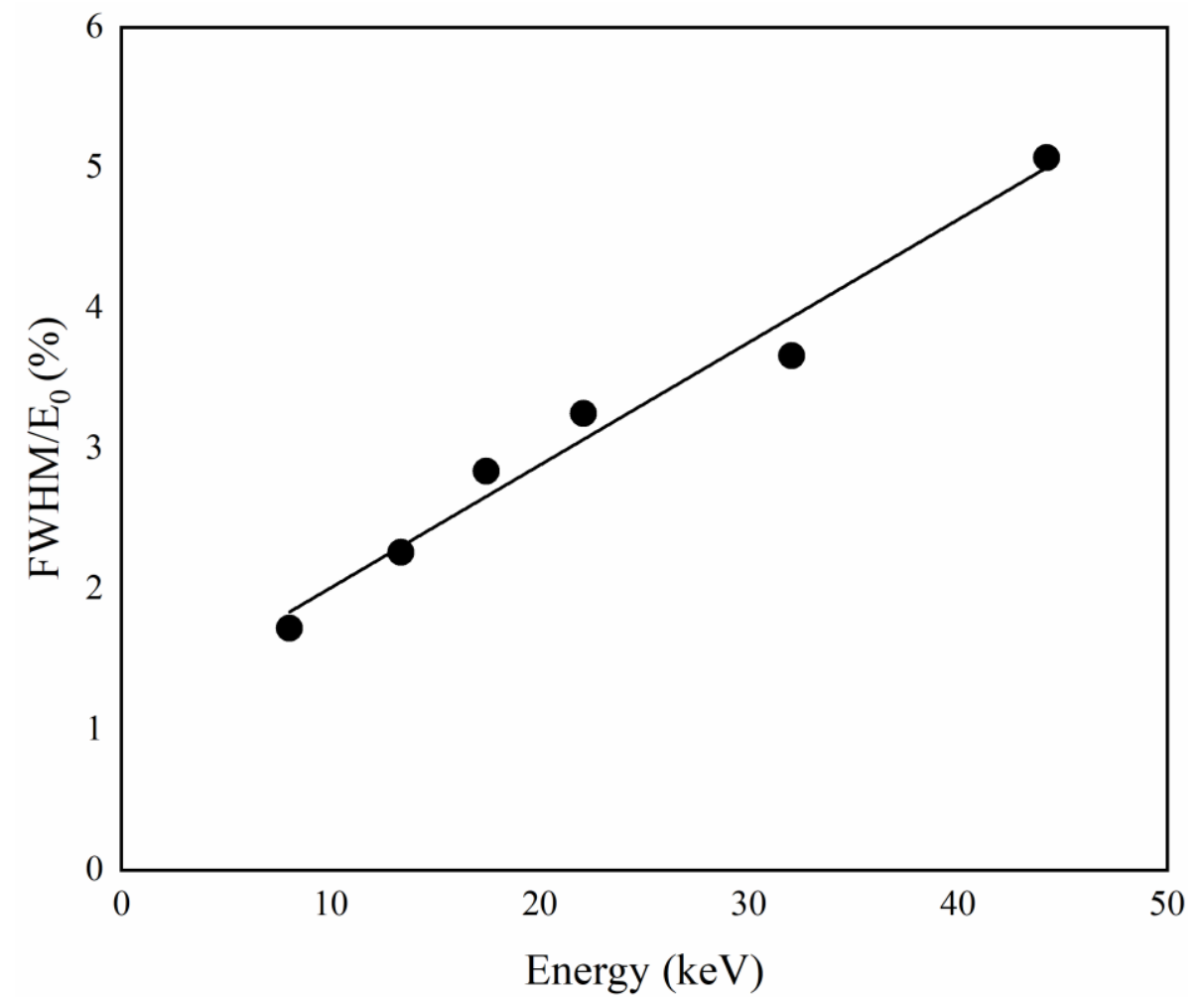

Figure 3. Energy resolution of the proportional counter against x-ray energy.

In this work, the emission spectra of variable $\mathrm{x}$-ray source was obtained. Characteristic $\mathrm{x}$-ray is characteristic of each element which results from transition of electron upon excitation of the atom. The measured energy of $\mathrm{K}_{\alpha}$ is displayed in Fig. 4 as a function of atomic number of the target. It was found that characteristic x-ray energy increases with the high atomic number of the target.

Fig. 5 can be shown that as the atomic number of the target increases, the $\mathrm{x}$-ay yield increases too. However, the last two points of the figure are questionable which the $\mathrm{x}$-ray yield decreased with atomic number of the target and then increases again. Thus, something must have gone wrong during measured of these two points. It has been shown that elements with high atomic numbers have high fluorescence yield. This is due to the high transition energy while the low atomic number of elements have low energy and yield. Also, this is attributed to the low energy of the Auger electron emission. 


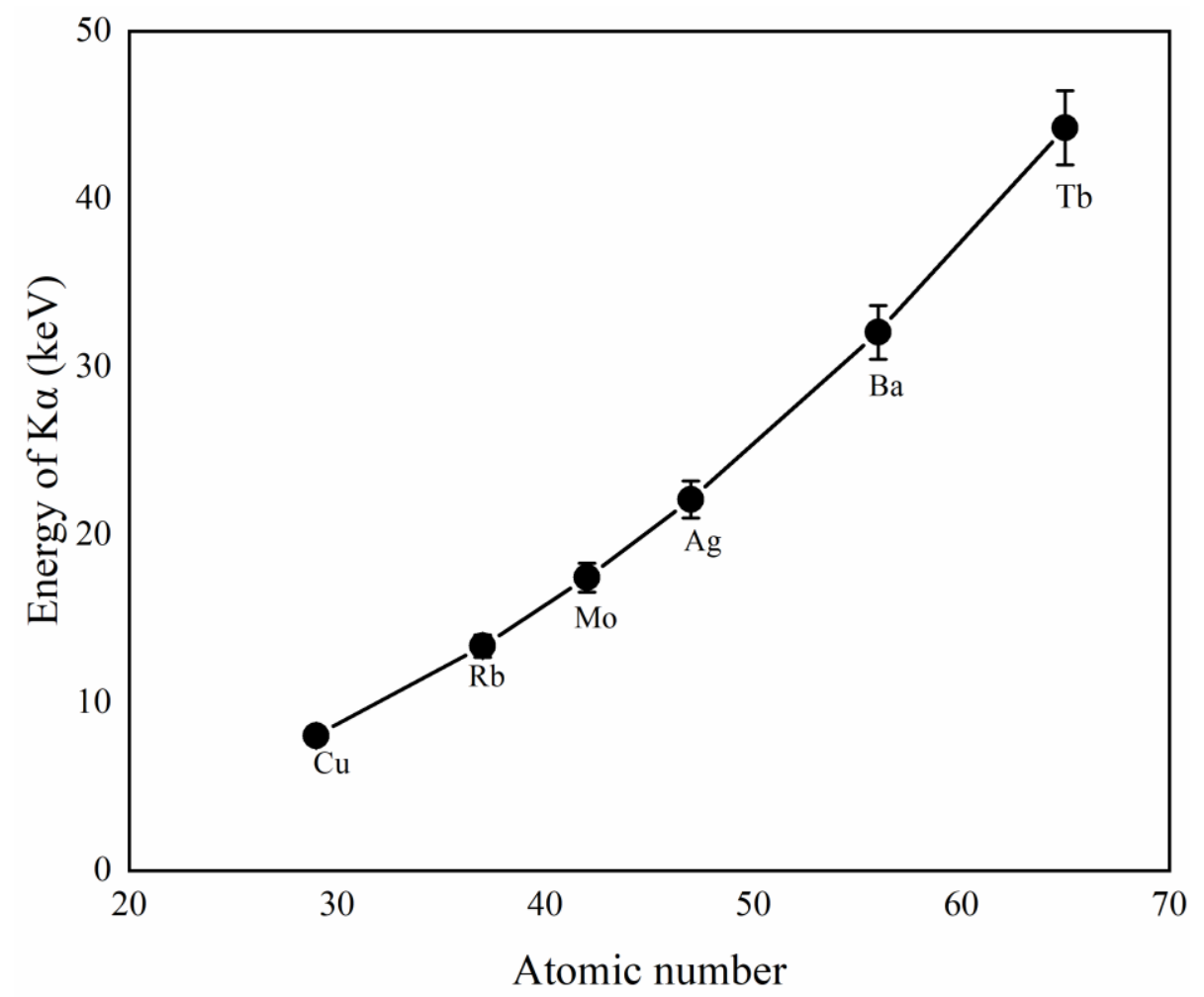

Figure 4. Energy of $\mathrm{K}_{\alpha}$ against atomic number of the target.

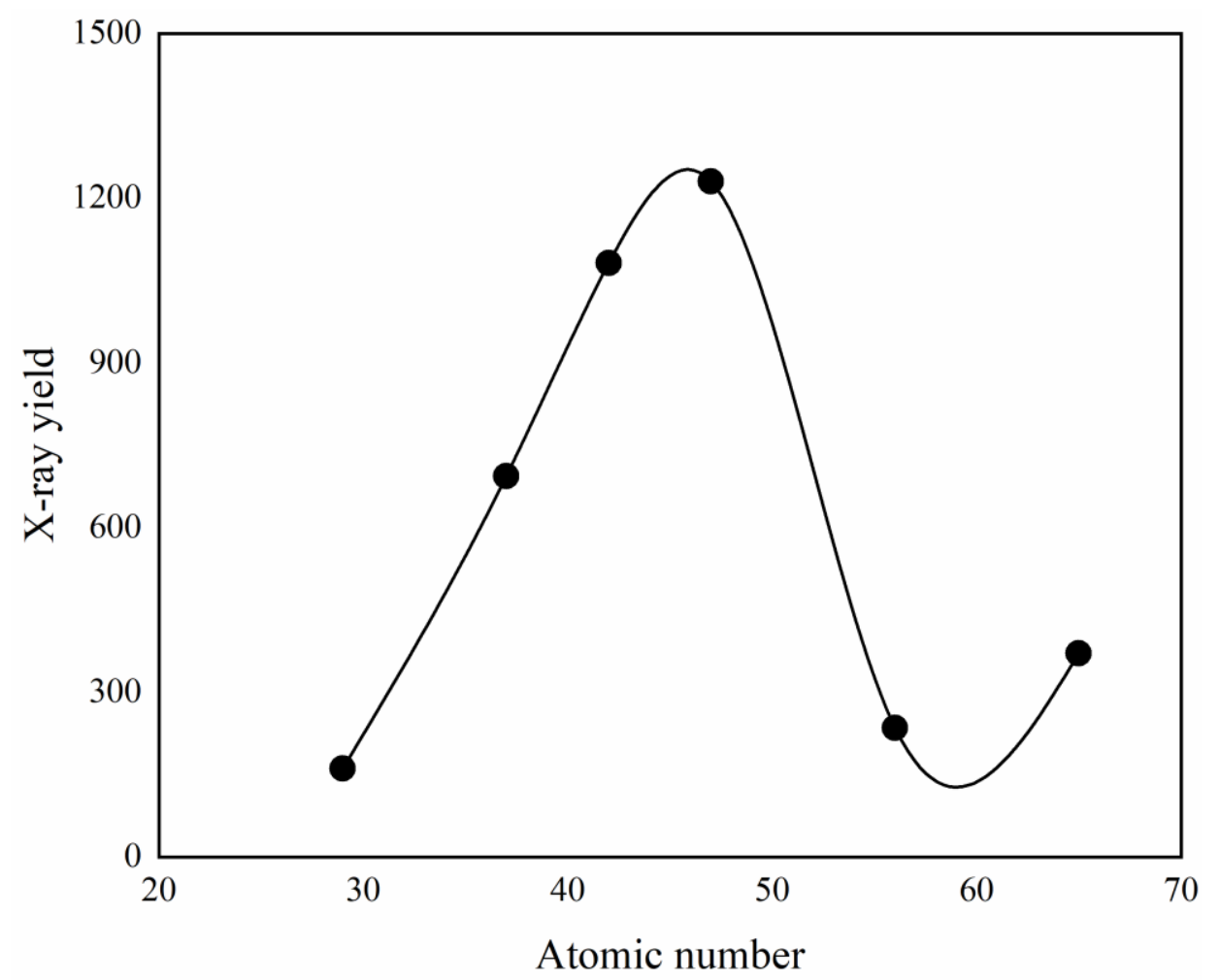

Figure 5. X-ray yield against atomic number of the target.

Different thicknesses of $\mathrm{Cu}(\mathrm{Z}=30)$ were used to produce $\mathrm{x}$-ray fluorescence from different $\mathrm{X}$ ray energies which are $1577.01,9855,17545$ and $48818 \mathrm{mg} / \mathrm{cm}^{2}$. X-ray fluorescence is produced by irradiating a copper foil using $\mathrm{Tb}$, Mo and $\mathrm{Rb}$ target. Fig. 6 shows that $\mathrm{X}$-ray yield 
did not change with low energy of Mo and $\mathrm{Rb}$ with increasing the thickness of the copper foil. However, the x-ray yield changes dramatically with high-energy x-rays (45.08 keV and 52.34 $\mathrm{keV}$ from $\mathrm{Tb}$ ) with increasing the thickness. Thus, $\mathrm{x}$-ray yield should be investigated further with high energy in relation to target thickness as there was no consistency in yield with increasing the thickness of the copper foil.

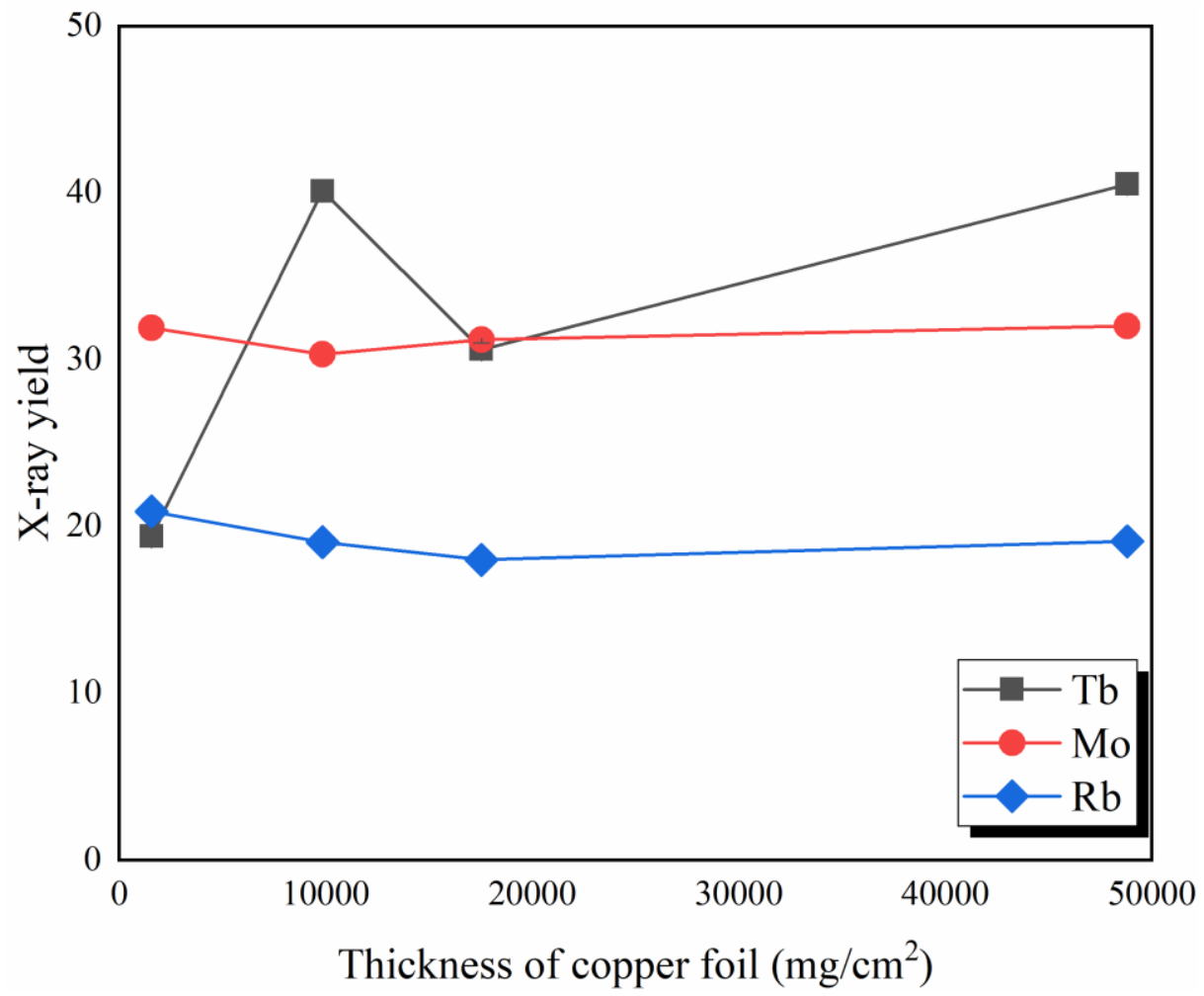

Figure 6. X-ray yield against thickness of copper foil.

\section{CONCLUSION}

In this work, a proportional counter was used to identify characteristic x-ray for six various targets. Characteristic x-ray or x-ray fluorescence is produced into two main mechanisms. The first is when an atom is excited by radioactive decay, internal conversion or electron capture. The second is by exciting the atom with external radiation, this external radiation can be a photon or a particle. The second method can be controlled in the sense that we can choose the exciting mean (photon or particle) as well as the target material.

\section{REFERENCES}

[1] H.M. Qadr, Calculation for gamma ray buildup factor for aluminium, graphite and lead, International Journal of Nuclear Energy Science and Technology 13(1) (2019) 61-69.

[2] D. Maiti, J. Zhong, Z. Zhang, H. Zhou, S. Xion, Z. Dong, S. Kumar, Z. Liu, K. Yang, Polyoxomolybdate (POM) nanoclusters with radiosensitizing and scintillating properties for low dose $X$-ray inducible radiation-radiodynamic therapy, Nanoscale Horizons 5(1) (2020) 109-118. 
[3] A. Wojcik, M. Harms-Ringdahl, Radiation protection biology then and now, International journal of radiation biology 95(7) (2019) 841-850.

[4] H. Qadr, Effect of Ion Irradiation on the Mechanical Properties of High and Low Copper, Atom Indonesia 46(1) (2020) 47-51.

[5] H.M. Qadr, A molecular dynamics calculation to cascade damage processes, The Annals of "Dunarea de Jos" University of Galati. Fascicle IX, Metallurgy and Materials Science 43(4) (2020) 13 16.

[6] H.M. Qadr, Radiation damage and dpa in iron using mcnp5, European Journal of Materials Science and Engineering 5(3) (2020) 109-114.

[7] M. Schütz, S. Procz, J. Fey, M. Fiederle, Element discrimination via spectroscopic X-ray imaging with a CdTe Medipix3RX detector, Journal of Instrumentation 15(01) (2020) P01006.

[8] L. Young, K. Ueda, M. Gühr, P.H. Bucksbaum, M. Simon, S. Mukamel, N. Rohringer, K.C. Prince, C. Masciovecchio, M. Meyer, Roadmap of ultrafast x-ray atomic and molecular physics, Journal of Physics B: Atomic, Molecular and Optical Physics 51(3) (2018) 032003.

[9] Y. Guo, Z. Yang, B. Hu, X. Wang, Z. Song, Q. Xu, B. Zhang, J. Chen, B. Yang, J. Yang, The continuous and discrete molecular orbital $x$-ray bands from Xe $q+(12 \leq q \leq 29)+Z n$ collisions, Scientific reports 6 (2016) 30644.

[10] M. Yao, D. Wang, M. Zhao, Element analysis based on energy-dispersive X-ray fluorescence, Advances in Materials Science and Engineering 2015 (2015) 290593.

[11] A.M. Hamad, H.M. Qadr, Gamma-Rays Spectroscopy by Using a Thallium Activated Sodium Iodide NaI (Ti), Eurasian Journal of Science and Engineering 4(1) (2018) 99-111.

[12] H.M. Qadr, Calculation of gamma-ray attenuation parameters for aluminium, iron, zirconium and tungsten, Problems of Atomic Science and Technology. Series:Thermonuclear Fusion 43(2) (2020) 2530.

[13] L. Strüder, N. Meidinger, D. Stotter, J. Kemmer, P. Lechner, P. Leutenegger, H. Soltau, F. Eggert, M. Rohde, T. Schulein, High-resolution X-ray spectroscopy close to room temperature, Microscopy and Microanalysis 4(6) (1998) 622-631.

[14] G.F. Knoll, Radiation detection and measurement, John Wiley \& Sons, 2010.

[15] F. Bartol, M. Bordessoule, G. Chaplier, M. Lemonnier, S. Megtert, The CAT pixel proportional gas counter detector, Journal de Physique III 6(3) (1996) 337-347.

[16] I. Akkurt, K. Gunoglu, S. Arda, Detection efficiency of NaI (Tl) detector in 511-1332 keV energy range, Science and Technology of Nuclear Installations 2014 (2014) 186798.

[17] Q. Mohammad, H. Maghdid, Alpha-particle stopping powers in air and argon, Journal of Pure and Applied Physics 5 (2017) 22-28.

[18] H.M. Qadr, A.M. Hamad, Using of Stopping and Range of Ions in Matter Code to Study of Radiation Damage in Materials, RENSIT 12(4) (2020) 451-456.

[19] H.M. Qadr, Comparison of Energy Resolution and Efficiency of NaI (TI) and HPGe Detector using Gamma-ray Spectroscopy, Journal of Physical Chemistry and Functional Materials 3(1) (2020) 24-27. 